\title{
An Ethical Analysis Model to DuPont's PFOA Event Based on Consequentialism Perspective
}

\author{
Zirui $\mathrm{Liu}^{1, *}$ Xintong $\mathrm{Li}^{2, *}$ Shang $\mathrm{Shi}^{3}$ \\ ${ }^{1}$ School of social science, Lingnan University, HongKong, HongKong 999077 \\ ${ }^{2}$ School of Business, University of Sussex, Falmer, Brighton, BN1 9RH \\ ${ }^{3}$ School of Business, University of Leicester, Leicester, LE1 7RH \\ *Corresponding author.Email: lxt1220@gmail.com, ziruiliu@ln.hk,ss1237@student.le.ac.uk
}

\begin{abstract}
Contemporarily, companies making unethical decisions when doing business is still a common phenomenon even facing hefty fines and reputation risk. In this paper, we focus on analyzing the consequences of DuPont's decision to dump chemical waste - perfluorooctanoic acid (PFOA, toxic chemical material) into air and local waterway since the 1940s during the production of its famous product Telfon. This action had led to a serious of severe consequences to its stakeholders and a long-lasting health issues, including birth defects, cancers, etc. Stakeholder analysis is adopted in order to discuss the effects on DuPont's four groups of stakeholders (employees, customers, the local resident, and the corporate itself) from the perspective of Consequentialism. According to the analysis of DuPont's ethical problems, companies should consider long term consequences of their stakeholders carefully when making decision. Eventually, proposals are put forward to address ethical issues, especially for chemical companies. Firstly, the government should improve the legal system and regulatory system as well as strengthen the supervision. In addition, social media is supposed to play an importing role in finding companies' unethical conduct and pressing on them. Lastly, in order to achieve sustainable success, it is critical for companies to raise the awareness and incorporate social responsibility into their own culture and strategies.
\end{abstract}

Keywords: Corporate Ethical Issues, Corporate Social Responsibility, Consequentialism, Stakeholder Analysis, Perfluorooctanoic Acid(PFOA)

\section{INTRODUCTION}

Large corporations, especially multinational ones, exert great influences on the economic, social and political environment of the countries they operate in. Societies in many countries are witnessing more and more intolerance of companies' unethical behaviors. The concept of Corporate Social Responsibility (CRS) has long been a popular topic in both research and practical world. Thereinto, most researchers believed that companies are ought to adhere to social and ethical standard when conducting business [1]. DuPont de Nemours Inc. (DuPont) is one of the world's largest producers of chemicals and science-based products, which was founded in 1902 and headquartered in Wilmington, Delaware, US. The company has a plentiful product line, e.g., elastomeric photopolymer printing plates, structural and elastic adhesives, reinforcing composites, foams, rubber and elastomers, topical ingredients, animal nutrition, biomaterials, fibers, and especially coating. DuPont has made many famous products through history including Teflon.

Teflon is a trade name given to polytetrafluoroethylene, a man-made chemical, which has been in commercial use since the 1940s. It has been widely used in non-stick cookware after its invention, i.e., frying pans with Teflon coating could be found in kitchens all around the world. Another man-made chemical worth mentioning is Perfluorooctanoic acid (PFOA). PFOA is a key element in the production of Teflon. PFOA is a highly stable and durable chemical which can stay and accumulate in water, soil as well as human blood [2]. Concerns over PFOA have been raised globally due to its persistent and bioaccumulate properties. Research has shown that exposure to PFOA is associated with serious health problems such as cancer and birth defects. Based on investigation of cancer incident in adult residents, Barry Winquist and Steenland [3] stated that PFOA is associated with kidney cancer and 
testicular cancer. Existing literature has also showed that prenatal exposure to PFOA will lead to adverse birth outcome [4]. Besides, both the carry over of PFOA from soil to plants (e.g., potatoes, oat and wheat [5]) and migration of PFOA in underground water [6] are crucial environment issues. These research reveals that PFOA can travel from soil to underground water and exist substantial long after the disposal by factories ceased. DuPont has the information about PFOA in hand since Teflon was invented, but they made a decision to sacrifice their social responsibility in pursuit of huge profit, i.e., purposely withheld this information for over fifty years. Corporate social responsibility has been widely discussed in both theoretical and managerial world. It is believed that companies are ought to meet the social obligations and comply to ethical standards when conducting business $[1,7]$.

In this paper, we identified DuPont's core ethical issue and offered series of suggestions to mitigate the potential ethical problems happening in two aspects. The deceived behavior of DuPont, by keeping information regarding POFA's toxic nature as a secret, led to many long-lasting consequences. From the consequentialism perspective, the ethical issue has been analyzed based on stakeholder analysis. The influences and impacts of the consequences are far-reaching since POFA can exist in the soil and water for decades and transmit through blood from generation to generation. Although DuPont harvested huge profit and fame by inventing and producing Teflon, short term profit is insignificant compared to the long term destruction to the environment and human body. The importance of corporate social responsibility should always be emphasized. We hope to provide some managerial implications to modern companies, especially those in the chemical industry. This paper provides some proposals to address ethical issues for chemical companies. Firstly, government should play an important role in supervising the chemical industry. Secondly, social media could be a powerfully tool in discovering companies' unethical behaviors. Nowadays people have easy access to the latest news from social media. Public opinion can exercise great pressure on unethical companies. Last but not the least, the importance of being ethical should be addressed to companies again and again. Companies should incorporate social responsibility as a key element in their decision-making process.

The remainder of this paper is organized as follow: Section 2 introduced the pecuniary condition of DuPont (including revenue, profits, assets and growth ratio) as well as its share performance (price, return ratio and volatility ratio) over the past five year. Section 3 identified DuPont's core ethical issues associated with the famous product Teflon. Section 4 provided an indepth analysis based on stakeholder analysis from the perspective of consequentialism theory in order to reveal the consequences of DuPont's decision. The consequences of DuPont's unethical conduct to four groups of its stakeholders have been discussed. Section 5 provided a discussion on DuPont's efforts to mitigate those consequences after the exposure of the Teflon scandal, as well as proposal for companies nowadays in relation to this kind of ethical issues. Section 6 is conclusion.

\section{DUPONT'S COMPANY BACKGROUND}

This section provides a holistic picture of DuPont's financial background. DuPont is still a world leading chemical company although affected by the ethical issue. After the exposure of DuPont's PFOA scandal, the company tried to provide clean water to the citizens as well as conducted issues to improve biopharmaceutical processing/delivery and health/fitness monitoring. Fig.1 shows the revenue, profit and total assets of DuPont in recent years, where one sees the revenue and profit of DuPont in recent years are generally declining. As illustrated in Figure 2, the stock price of DuPont showed an overall upward trend from 1985 to 2020. However, there were three major fluctuations in 2009, 2018 and 2020 , respectively, which is also proved by the validation evolution in Fig. 3.

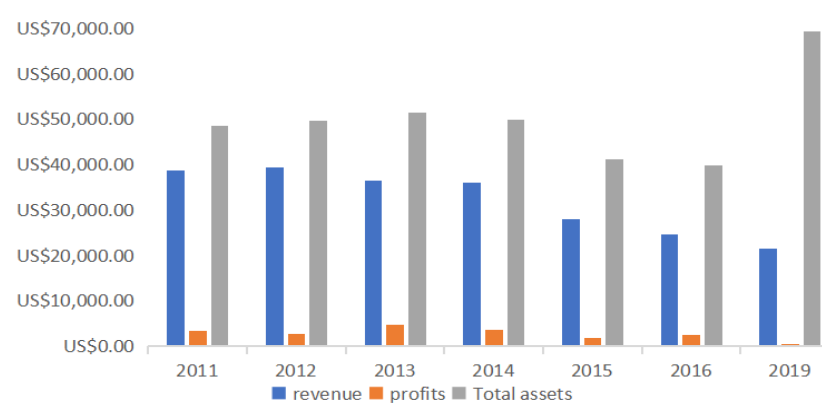

Figure 1: Revenue, profits, and total assets of DuPont from $2011-2019$.

The above data are from https://finance.yahoo.com/quote/DD?p=DD\&.tsrc=finsrch

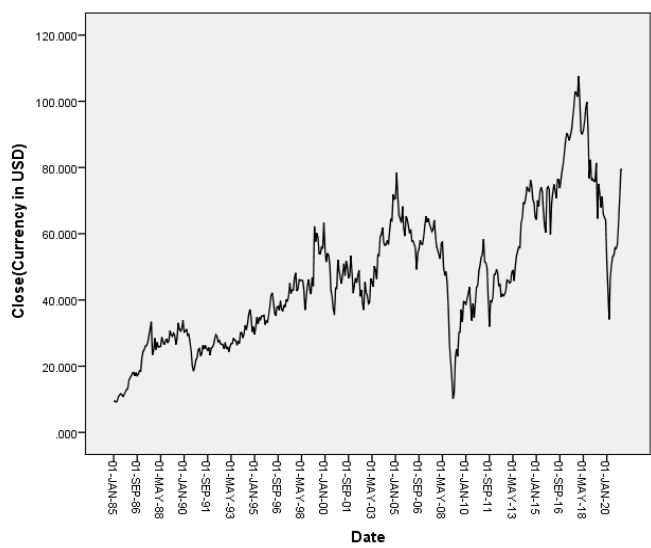


Figure 2: DuPont stock closing price as a function of date.

The above data are from https://inance.yahoo.com/quote/DD?p=DD\&.tsrc=finsrch

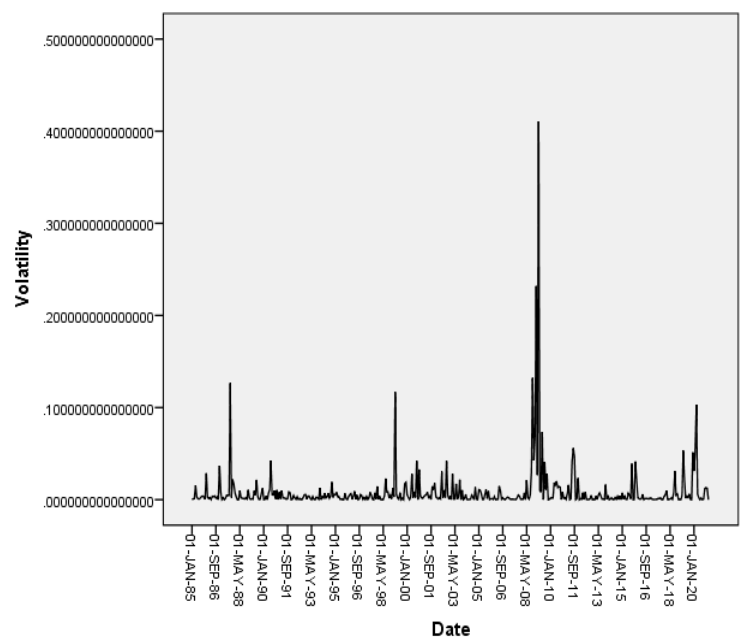

Figure 3: DuPont stock volatility as a function of date

Table 1: DuPont stock' price, return and volatility in recent years

\begin{tabular}{llll}
\hline Date & Close & Return & Volatility \\
\hline 2016 & 73.40000 & .1340591825 & .0179718644 \\
2017 & 83.93000 & -.097724626 & .0095501025 \\
2018 & 76.11600 & -.170255282 & .0289868610 \\
2019 & 64.20000 & .1022247632 & .0104499022 \\
Average & 74.41150 & -.007923990 & .0104499022 \\
\hline
\end{tabular}

As a matter of fact, the return rate and volatility of DuPont stock price can be calculated as

$$
\begin{aligned}
& \text { Return }=\ln \left[P_{t+1} / P_{t}\right] \quad \times 100 \% \\
& \text { Volatility }=\text { Return }{ }^{2}
\end{aligned}
$$

The corresponding results in recent years obtained from Eq.(1), (2) are listed in the Table 1.It is clear that the close price and the return reached minimum in 2019 and 2018 respectively. The minimum close price is 64.2 dollar and the minimum return reached -0.17 . Meanwhile, its volatility was highest in 2018 and lowest in 2017. Overall, DuPont's operating condition is good through the above data. Nevertheless, in addition to the company size large and well-known outside, more and more people realize this infamous sewage event, especially after the documentary named "Blackwater". Subsequently, we will focus on the event, the core of the moral problems.

\section{THE CORE ETHICAL ISSUE OF DUPONT}

The DuPont's core ethical issue is covering up of the toxic nature of PFOA and its potential harm to human body. This unethical conduct has led to a series of consequences to its stakeholder.

DuPont had been purposely held this information as a secret to its workers and surrounding residents until Wilbur Tennant, a cattle famer who lived near DuPont's Teflon plant in Parkersburg, filed a law suit against DuPont. Over 200 of his cows died and he believed it was due to the contamination of local water and DuPont shall be held liable for this consequence [8]. Since then, the true colors of Teflon have been slowly revealed to the world. Subsequently, a class action was filed by the same lawyer in 2001 representing 80,000 residents living in the area where PFOA had leaked into the water supply. Scientists have proved that PFOA is associated with many diseases, e.g., kidney cancer, thyroid disease and abnormal liver function (American Cancer Society). Therefore, numerous individual lawsuits were filed against DuPont by victims who suffered from PFOA related diseases. The litigation did not come to an end until 2017, when DuPont had paid $\$ 671$ million over 3550 lawsuits in total, including but not limited to paying compensation to victims, building filter plants to treat the chemicals before disposal, and developing sustainable solutions. The deception led to many other severe consequences to human bodies, such as birth defect. Buck Bailey, whose mother worked as a normal operator at DuPont's Teflon plant in 1980, was born with only one nostril and severe facial deformities. By the time Bailey entered 30's, he has undergone 30 surgeries [9].

By the time the harmfulness of PFOA is known to the world, it is detected in the serum of $99 \%$ of Americans. Instead of reduce Teflon production, DuPont double the disposal of PFOA into air and local airways after comparing the societal benefit and cost of keep using PFOA [10]. Their research revealed that the DuPont's decision at the time demonstrated ignorance and poor corporate governance. They also took advantage of the incomplete legal system since the local court rejected cases regarding chemical emission at that time. The next session will provide an in-depth analysis on the consequences of DuPont's unethical conduct to its stakeholders.

\section{ETHICAL ISSUE ANALYSIS}

This section further discusses the impacts of DuPont's decision to its stakeholders, adopting the theory of consequentialism and stakeholder analysis.

\subsection{Theoretical Support}


Consequentialism is politically popular since it seeks to achieve the greatest good for the greatest number of people. A major branch of consequentialist thought is utilitarianism, a term derived from a useful synonym, utility. This suggests that philosophy is about people, society and justice, which is on the surface desirable [11]. In order to applying this principle, the definition of a good outcome and the audience of the good outcome should be considered.

In this article, we focus on four stakeholders: employees, consumers, residents and company itself. The results for each of these four aspects are discussed and the principles of consequentialism are applied to make a comprehensive analysis of the overall results.

\subsection{Stakeholder Analysis}

\subsubsection{Dupont's Employees}

For employees, the result is that birth defects found in mothers working at DuPont. The company monitored the babies of female employees who worked with PFOA and became pregnant during the relevant time. They found detectable levels of PFOA in cord blood, suggesting that it can indeed be transmitted through the human placenta. Besides, two of the seven babies monitored were born with defects in the eyes and nostrils, indicated the serious consequences [12]. A birth defect affects not only a family but also a child's entire life, i.e., the outcome for the employee is extremely bad.

\subsubsection{Consumers}

For consumers, the dangers of Teflon nonstick pans are also worth treating with caution. Non-stick fry pans can release toxins. At high temperatures, Teflon is known to give off a cocktail of 15 types toxic particles and gases, including trifluoroacetic acid (TFA) and phosgene. These chemicals are known to be poisonous to birds. With regard to humans, they cause headaches, chills, backache, and fever - a condition known as 'Teflon flu'. DuPont acknowledged this but said that the condition is reversible and only occurs at high temperature while not during normal cooking. However, the Environmental Working Group (EWG), an independent US non-profit consumer group, disputes this. It argues that Teflon begins to deteriorate after the temperature of cookware reaches about $260^{\circ} \mathrm{C}\left(500^{\circ} \mathrm{F}\right)$, and begins to significantly decompose above $350^{\circ} \mathrm{C}\left(660^{\circ} \mathrm{F}\right)$. Cooking fats, oils and butter will begin to scorch and smoke at about $200^{\circ} \mathrm{C}$ $\left(392^{\circ} \mathrm{F}\right)$, and meat is usually fried between $200-230^{\circ} \mathrm{C}$ $\left(400-450^{\circ} \mathrm{F}\right)$, but hot spots in the pan can easily exceed this temperature. Off-gassing can occur when a Teflon pan is left unattended. A Teflon pan can reach $383^{\circ} \mathrm{C}$ $\left(721^{\circ} \mathrm{F}\right)$ in just five minutes heated on a conventional, electric stovetop, says the EWG. Despite all the culinary convenience that the use of nonstick pans brings to consumers, according to consequentialism. Nevertheless, any convenience that is premised on or at the risk of sacrificing health cannot be defined as good. Thus, to some extent, forgoing Teflon nonstick pans may be a smart choice for consumers.

\subsubsection{Residents}

For residents, they have suffered great long-term damage from this incident. Blood samples were collected from 382 residents (58\% response rate) from Dordrecht and Papendrecht in the fall of 2016, where PFOA was determined. Participants were able to know the level of PFOA presence in their blood. [13]. In 1981, DuPont learned further that PFOA could be harmful, but they did not notify regulators or nearby communities of the new findings [12]. As a consequence, tenants lost their cattle in a distressing manner. Bilot was an excellent lawyer who had worked on the Tennant case for twenty years. He successfully went to court to get DuPont to release all documents about the substance. The documents he obtained -- 110,000 pages of documents that are about half a century old and took months to put together -- show that the company dumped 7,100 tons of PFOA sludge into the landfill, and that sewage from the landfill flowed into the tenants' properties [14]. Therefore, from a consequentialism point of view, the result is a huge blow to the health and property of the residents.

\subsubsection{Company}

For company, ethical tendencies within an organization influence views of justice and administrative policy [15], i.e., it must have believed that the benefits outweighed the costs before the decision. Harmful pollution is a rational decision: with a reasonable probability of detection, pollution is the best choice beforehand from the company's point of view, even though it is a very harmful decision from the society's [10]. In the short term, DuPont made a lot of money from the product and saved the cost of dealing with the contaminants. However, in the long term, the company's reputation was damaged by the exposure and compensated a lot of fines afterwards. Thus, even DuPont has suffered a huge loss. So far, it seems that from a consequentialist point of view there are no beneficiaries.

\section{DISCUSSION}

To solve this problem, DuPont has indeed made some improvement and compensation. Whereas, these measures are unable to offset the pollution event damage to people. Furthermore, it can't completely put an end to the other medium enterprises at the expense of the people's health and the environment to develop the economy. Therefore, some corrective actions are needed to constantly improve the system of the industry. 


\subsection{The Efforts and Reparations DuPont has made}

It should be noted that DuPont also took a series of measures, though these measures did not fundamentally solve the vicious pollution incident to the public harm. In 1981, DuPont learned further that PFOA could spread from pregnant women to babies, causing human birth defects. Hence, they moved women from the PFOA division until the level of exposure is below than potential hazard ratio [12]. In 2017, DuPont assembled a panel of scientists to determine if there were any illnesses linked to PFOA. The team concluded that this could be linked to six conditions: kidney and testicular cancer, ulcerative colitis, thyroid disease, high blood pressure during pregnancy and high cholesterol. DuPont Inc. and Chemours Inc. paid \$671 million in cash to settle thousands of lawsuits over the spill of a toxic chemical used to make Teflon.

\subsection{Proposals on DuPont's Ethical Issues}

DuPont is absolutely not the only company having ethical issue, in fact, there are many such cases all over the world, e.g., Nestle and Nike scandals. Ethical problem is common among big corporations and some measures are urgently required to regulate them. Thus, proposals are offered addressing ethical problems for chemical companies from three perspectives, the government, social media, and corporate governance.

\subsubsection{The Legal System}

As in October 2011, 3,535 plaintiffs had filed personal injury suits against DuPont. DuPont could fight each law suit individually, which is a strategy used by tobacco companies to fight personal-injury suits. In this case, DuPont will continue to fight the PFOA case at the rate of four trials a year until 2890. The as long as possible delays payment for litigation will encourage similar firms to pollute more recklessly at the expense of their economies. A simple way to mitigate the problem would be to improve the litigation system, which abandon companies to defend themselves individually against all victims in the cases.

\subsubsection{Regulatory}

On one hand, the government needs to further strengthen the supervision of various enterprises in society to effectively curb these immoral business activities. At present, the negative effects of the actual business models and behaviors of most enterprises often violate their commitments to people and the natural environment [16]. As a result, an increasing number of people ask the government and relevant legal departments to take some effective methods to restrict the activities of enterprises. Another study also shows that government regulation can effectively curb unethical business activities, such as green cleaning [17]. By means of more binding regulatory, these enterprises will unable do wanton behavior that endangers the whole social development and ecosystem. Thereby, the safety of citizens and the natural environment will be greatly protected. On the contrary, if the government and other state institutions still do not properly monitor and control these immoral business activities, the personal interests and the future development of the whole ecosystem will be greatly affected. Therefore, government regulation plays an important role in reducing and preventing the damage caused by business activities.

\subsubsection{Detection}

The government should set up a professional testing team to examine how chemical waste is being treated by the company before any new product is launched. On one hand, DuPont was able to dispose this kind of chemical waste decades ago due to the information being hidden by the company. On the other hand, it indicated the failure of government's detections, supervision and control. Therefore, government should set up new material testing teams to check the new product of enterprise and only qualified products can be put into production. Perfluorinated alkylated substances (PFAs) were invented in the 1930s and became a widely used component in commercial and industrial products in the 1950s. Throughout the second half of the 20th century, PFAs were a major ingredient in many everyday products, including non-stick kitchen utensils, shampoos, microwave popcorn bags, and car wax. PFAs also have industrial uses, especially in paper and packaging, metal plating, carpets and fire-resistant foams. Despite their rapid and widespread introduction into consumer products, PFAs have been unregulated for decades under the Toxic Substances Control Act (TSCA) [18]. This also reflects the loopholes in the detection and supervision of new substances. Therefore, the government should increase research investment in this field to make the detection of new substances as efficient and accurate as possible.

\subsubsection{Social Media}

As for enterprises, they should not only focus on immediate interests but also pay attention to the future development of the whole society. Thus, social media should increase the exposure of enterprises to further monitor the business activities related to people's health and natural environment carried out by various enterprises in the market. Contemporarily, with the rapid development of economy and technology, there are a series of mobile devices on the market, e.g., smartphones and tablet computers, which make it easier for people to access social media. A recent report showed that nearly 4 billion people around the world use social media for about 
two hours a day on average. Moreover, this number is still growing, with an increasing number of people beginning to spend more time on social media on the Internet [19]. In other words, the power of social media cannot be underestimated. Another recent study also demonstrated that social media as well as the operation and development of the enterprise are also more and more strong relating. In this case, social media can be a huge impact on an enterprise [20]. If a social media promote the right values to the citizen and society, e.g., the importance of the protection of ecologically sustainable development and maintenance of the necessity of people's life safety, the enterprise will suffer from more regulation of the public. Consequently, those who destroy the citizens' physical condition and natural environment of unethical business activities will be greatly reduced. To sum up, social media plays an important role in raising the awareness of environmental protection among citizens and controlling unethical business practices.

\subsubsection{Proposals to DuPont and other chemical companies}

Chemicals are playing an important role in every aspects of people's daily life. This paper also gave some suggestions for chemical companies with DuPont's managerial level. To begin with, the awareness of being ethical must be address. It is important to make sure that the top management level of a company understand the importance and seriousness of social responsibility. Therefore, their decision should not harm anybody directly or indirectly. Companies should integrate higher level of social responsibility into their mission, vision and corporate culture.

Secondly, companies should incorporate social responsibility and consider the long-term consequences to their strategy and decision-making process. The theory of consequentialism could be applied in this process. Companies can list out all the possible consequences to all the parties involved before the final decision is made.

Last but not least, chemical companies are usually large in size, and have difference factories in different location. In this case, many problems may arise during their daily operations. The implementation of ethical strategies may face many obstacles. Companies should engage or set up a professional supervision and enforcement team to ensure that the implementation of strategies adhered to the ethical standards.

\section{CONCLUSION}

In summary, the DuPont's Teflon (with the toxically component PFOA) incident has been analyzed and explored based on stakeholder analysis from the perspective of Consequentialism. Back to the 1940s, the results of dumping PFOA directly into local airway might outweigh the outcome of not doing so. However, if the company could take a longer-term perspective, it is obvious that the consequences of doing so are devastating to the environment, human health, as well as the company's reputation. DuPont's stakeholders have suffered a huge loss because of this incident. Relevant suggestions are put forward from the perspective of the government and social media in order to further reduce unethical business activities as well as encourage enterprises to form a sustainable development model centered on environment and people. As for the government, they should adopt a stricter supervision system, perfect the litigation mechanism as well as set up special reconnaissance agencies. With regard to social media, it is ought to increase the visibility of enterprises for the sake of better monitored and restricted. These results offer a guideline to regulate the corporate unethical behavior. Further studies should investigate and focus on other perspective that reduce and avoid more serious harmful business activities

\section{REFERENCES}

[1] Adam Lindgreen, Velerie Swaen (2010) Corporate Social Responsibility, International Journal of Management Reviews. 12:1-7.

[2] Gloria B. Post, Perry D. Cohn, Keith R. Cooper (2012) Perfluorooctanoic acid (PFOA), an emerging drinking water contaminant: A critical review of recent literature. Environmental Research 116: 93 117

[3] Vaughn Barry, Andrea Winquist, Kyle Steenland (2013) Perfluorooctanoic acid (PFOA) exposures and incident cancers among adults living near a chemical plant. Environmental Health Perspectives 121(11-12): 1313-1318.

[4] Kusheng Wu, Xijin Xu, Lin Peng, Junxiao Liu, Yongyong Guo, Xia Huo (2012) Association between maternal exposure to perflurooctanoic acid (PFOA) from electronic waste recycling and neonatal health outcomes. Environment International 48:1-8.

[5] T. Stahl, J. Heyn, H. Thiele, J. Huther, K. Failing, S. Georgii, H. Brunn (2009) Carryover of Perfluorooctanoic Acid (PFOA) and Perfluorooctane Sulfonate (PFOS) from Soil to Plants. Arch Environ Conta Toxicol, 57:289-298

[6] Feng Xiao, Matt F. Simcik, Thomas R. Halbach, John S. Gulliver (2015) Perfluorooctane sulfonate (PFOS) and perfluorooctanoate (PFOA) in soils and groundwater of a U.S. metropolitan area: Migration and implications for human exposure. Water Research, 72: 64-74. 
[7] Smith N. Craig. 2003. Corporate Social Responsibility: Whether or How? California Management Review, 45(4) 52-77.

[8] Nathaniel Rich. 2016. The Lawyer Who Became DuPont's Worst Nightmare [online] The New York Times Magazine. Available at <https://www.nytimes.com/2016/01/10/magazine/t he-lawyer-who-became-duponts-worstnightmare.html> [Accessed 5 February 2021]

[9] Jeff Mordock. 2016. C8 suspected in birth defects: one women's story. [online] Delaware Online. Available at <https://www.delawareonline.com/story/news/201 6/04/02/c8-suspected-birth-defects-one-womansstory/81473242/ > [Accessed 05 February 2021]

[10] Schoenmaker, D. (2020). The impact economy: balancing profit and impact. Bruegel Working Paper July 2020.

[11] Ellis, P. (2019). Ethical concepts: the meaning of consequentialism. Journal of Kidney Care, 4(5), 274-276.

[12] Shapira, R., \& Zingales, L. (2017). Is pollution value-maximizing? The DuPont Case (No. w23866). National Bureau of Economic Research.

[13] Van Poll, R., Jansen, E., \& Janssen, R. (2017). PFOA measurements in blood: Measurements in serum in residents around DuPont/Chemours in Dordrecht, The Netherlands

[14] Simon Ward. 2020. The man winning the war on toxic waste. [online] Street Roots. Available at <https://www.streetroots.org/news/2020/02/28/ma n-winning-war-toxic-waste $>$ [Accessed 01 February 2021]

[15] Love, E., Salinas, T. C., \& Rotman, J. D. (2020). The ethical standards of judgment questionnaire: Development and validation of independent measures of formalism and consequentialism. Journal of business ethics, 161(1), 115-132.

[16] Martens, J. and Seitz, K., 2017. 12. Binding Rules On Business And Human Rights - A Critical Prerequisite To Ensure Sustainable Consumption And Production Patterns. [online] 2030spotlight.org. Available at: <https://www.2030spotlight.org/en/book/1165/cha pter/12-binding-rules-business-and-human-rightscritical-prerequisite-ensure> [Accessed 23 January 2021].

[17] Sun, Z. and Zhang, W., 2019. Do government regulations prevent greenwashing? An evolutionary game analysis of heterogeneous enterprises. Journal of cleaner production, 231, pp.1489-1502.
[18] Richard Head JD, M. S. E. S. (2019). PFAS Regulations: How We Got Here and How to Recover the Costs. Journal of the New England Water Works Association, 133(4), 239-242.

[19 ] Henderson, G., 2020. How Much Time Does The Average Person Spend On Social Media?. [online] Digitalmarketing.org. Available at: <https://www.digitalmarketing.org/blog/howmuch-time-does-the-average-person-spend-onsocial-media> [Accessed 23 January 2021].

[20] Smits, M. and Mogos, S., 2013. The impact of social media on business performance. ECIS 2013 Completed Research. 125. 